\title{
Recombinant protein sub-unit vaccine synthesis in microbes: a role for yeast?
}

Roslyn M. Bill

School of Life and Health Sciences, Aston University, Birmingham, B4 7ET, UK

Correspondence: Roslyn M. Bill, School of Life and Health Sciences, Aston University, Aston Triangle, Birmingham, B4 7ET, UK

r.m.bill@aston.ac.uk

Keywords: yeast, Saccharomyces cerevisiae, Pichia pastoris, recombinant antigen.

\section{Abstract}

Recombinant protein sub-unit vaccines are formulated using protein antigens that have been synthesized in heterologous host cells. Several host cells are available for this purpose, ranging from Escherichia coli to mammalian cell-lines. This article highlights the benefits of using yeast as the recombinant host. The yeast species, Saccharomyces cerevisiae and Pichia pastoris, have been used to optimize the functional yields of potential antigens for the development of sub-unit vaccines against a wide range of diseases caused by bacteria and viruses. S. cerevisiae has also been used in the manufacture of eleven approved vaccines against hepatitis B virus and one against human papillomavirus; in both cases the recombinant protein forms highly-immunogenic virus-like particles. Advances in our understanding of how a yeast cell responds to the metabolic load of producing recombinant proteins will allow us to identify host strains that have improved yield properties and enable the synthesis of more challenging antigens that cannot be produced in other systems. Yeasts therefore have the potential to become important host organisms for the production of recombinant antigens that can be used in the manufacture of sub-unit vaccines or in new vaccine development.

\section{Recombinant protein sub-unit vaccines}

Most vaccines are based on formulations comprising either live, attenuated- or killed, inactivated-bacteria or viruses (1). Live, attenuated vaccines typically induce strong, longlasting immunity; however, while they are attenuated in their pathogenicity, concerns remain 
about reversion to virulent wild-type strains that might cause disease in immunocompromised individuals (2). In contrast, killed, inactivated vaccines are noninfectious (2), but are less effective in inducing protective immunity often requiring an adjuvant to stimulate antibody responses and effector T cell functions (3). The increasingly stringent demands of regulatory authorities such as the United States Food and Drug Administration (FDA), the European Medicines Agency (EMA) and the World Health Organization (WHO) require new vaccine compositions to be precisely specified. This makes developments using whole cell vaccines particularly challenging because they contain undefined molecules that originate from the source bacterium or the host cell used to produce the virus.

In the last thirty years, there has been a trend towards developing sub-unit vaccine formulations that contain defined antigenic components together with a potent adjuvant (2). The antigen may be a polysaccharide, a nucleic acid or a protein. In the latter case, which is the focus of this article, the protein itself may be (i) a purified protein from the diseasecausing pathogen, (ii) a synthetic peptide or (iii) a recombinant protein that has been synthesized in one of many possible heterologous host cells ranging from Escherichia coli to mammalian cells (4). This ensures that the antigen has a well-defined composition, that there is effectively no risk of pathogenicity in its use and that antigen synthesis and purification can be scaled up in a cost-effective manner (5). Unfortunately, while many recombinant proteins exhibit immunogenicity in mice, they are not necessarily potent antigens in humans (even when administered with an effective adjuvant), as seen in the case of apical membrane antigen-1 (AMA-1), which is a leading blood-stage malaria vaccine antigen (6). However, some recombinant proteins form virus-like particles (VLP), which are multi-protein structures that mimic the organization and conformation of native viruses but without a viral genome (7). VLPs have been found to be more stable and considerably more immunogenic than purified protein antigens (7). Notably, the two currently-licensed 
recombinant antigens manufactured in yeast are VLPs (Table 1). This review examines the role that yeast cells can play in further vaccine development.

Recombinant gene expression technology was developed 41 years ago in $E$. coli (9), leading to the recombinant synthesis of the human hormones, somatostatin in 1977 (10) and insulin in 1979 (11). Today, the production of a wide range of recombinant biopharmaceuticals, including recombinant hormones, antibodies and vaccines, is a multi-billion dollar global business (12). More than 150 biopharmaceuticals have been approved by the FDA to date $(13,14)$, with approximately $20 \%$ of these recombinant proteins being produced in yeasts (the vast majority in S. cerevisiae), 30\% in E. coli and 50\% in mammalian cell-lines and hybridomas $(5,13,15)$. Table 1 summarizes data for recombinant protein sub-unit vaccines that are either currently licensed for human use in the EU or the US or have previously been licensed but are now withdrawn. In contrast to the picture for biopharmaceuticals as a whole, it is notable that the majority of commercial vaccines use antigens that have been synthesized in microbes; 14 out of the 16 vaccines in Table 1 contain an antigen synthesized in either E. coli or S. cerevisiae although only two distinct antigens are actually synthesized in S. cerevisiae and two in E. coli. Recombinant hepatitis B surface antigen (HBsAg) synthesized in S. cerevisiae has been used in 11 different formulations (Table 1); the first of these was reported in 1982 (16) and was subsequently licensed in 1986 by the FDA for use in humans (2). Due to a lack of demand in the EU, GlaxoSmithKline Biologicals withdrew Tritanrix-HB $^{\circledR}$ in 2009, while Aventis Pasteur MSD withdrew Primavax ${ }^{\circledR}$ in 2000 and Procomvax $^{\circledR}$ in 2009 , all of which contain recombinant HBsAg as part of multivalent vaccine formulations. A second antigen synthesized in S. cerevisiae is comprised of the major capsid protein, L1, from four human papillomavirus types $(6,11,16$ and 18) to generate the human papillomavirus vaccine, Gardasil ${ }^{\circledR}$. In both cases these $S$. cerevisiaederived antigens form VLPs. An alternative VLP vaccine, Cervarix ${ }^{\circledR}$, is formulated using recombinant major capsid protein, L1, from two human papillomavirus types (16 and 18) that 
81

have been synthesized in insect cells; insect cells are also used in the manufacture of a second vaccine, Flublok ${ }^{\circledR}$ (Table 1).

In 1998, a vaccine against Lyme disease, Lymerix ${ }^{\circledR}$, was approved by the FDA. Lymerix ${ }^{\circledR}$ incorporates recombinant surface lipoprotein, OspA, from Borrelia burgdorferi that is synthesized in E. coli (Table 1); however, the vaccine was withdrawn by the manufacturer in 2002 due to a lack of demand in the US that followed extensive media coverage and ongoing litigation concerning adverse side effects (17). This was despite initial studies indicating that the Lymerix ${ }^{\circledR}$ vaccine was a cost-effective public health intervention for people at high risk of Lyme disease; its withdrawal precluded the design of more conclusive studies (18). Bexsero ${ }^{\circledR}$ was licensed in the EU in 2013 to protect against meningococcal meningitis and septicemia caused by meningococcal serogroup B (Table 1). It contains three antigens synthesized in $E$. coli in addition to an outer membrane vesicle from meningococcal strain MZ98/254.

Recombinant antigen synthesis is possible in a range of host cells: the importance of Escherichia coli

E. coli is typically the first choice of host cell for producing recombinant proteins in industrial and academic laboratories; it is a familiar laboratory organism, quick and inexpensive to culture and has the potential to generate high product yields (5). Unsurprisingly, it is therefore widely used in both commercial (for the manufacture of approximately $30 \%$ of protein biopharmaceuticals; $(13,15)$ ) and research (in the synthesis of $>70 \%$ of proteins $(5)$ ) laboratories. This situation is reflected by data in the published literature on recombinant antigen synthesis, which suggests a wide range of protein antigens have been produced in E. coli for use in the development of new recombinant protein sub-unit vaccines: on $8^{\text {th }}$ October 2014, the PubMed Central database was searched for entries in any field containing "recombinant" and "vaccine" together with the name of the host cell; this returned 3,256 articles for "coli", 266 articles for "pastoris", 288 articles for "cerevisiae", 890 articles for "baculovirus" and 398 articles for $\mathrm{CHO}$ (or 107 articles for "Chinese hamster ovary"). While 
this type of analysis can only be indicative, E. coli does appear to have an important role in research into recombinant antigens, in line with its wider use in recombinant protein production.

Reports using E. coli as the host cell most often describe initial characterization of the recombinant antigen and demonstration of immunogenicity in mice, as illustrated by the following examples. Recombinant protective antigen (rPA83) has been characterized as a successful adjuvant-bound sub-unit vaccine against Bacillus anthracis, the causative agent of anthrax (19). Recombinant fraction 1 (Caf1) and $\vee$ (LcrV) antigens induce protection against Yersinia pestis infection (the causative agent of bubonic and pneumonic plagues) one year post-vaccination (20). Flaccid paralytic disease or botulism is caused by neurotoxin $\mathrm{F}$ from Clostridium botulinum; the receptor-binding domain of neurotoxin $\mathrm{F}$ was synthesized as a fusion with or without maltose binding protein in $E$. coli and the purified protein protected mice against challenge with $C$. botulinum neurotoxin $F$ ten months after vaccination (21). Helicobacter pylori infection causes stomach and duodenal ulcers in humans; the recombinant urease sub-units, UreA and UreB, induced an immunoprotective response in mice (22). Hospital-acquired infection such as pneumonia and sepsis are typically caused by Staphylococcus aureus. Data from studies in mice have suggested the potential to develop a protein sub-unit vaccine based on recombinant collagen binding bacterial adhesin fragment (CNA19) (23). A proof-of-principle leprosy vaccine development scheme recently demonstrated efficacy in mice using a $73 \mathrm{f}$ fusion protein (coded by aligning the individual gene sequences for ML2028, ML2346 and ML2044 from Mycobacterium leprae as a single product) (24). Two approaches to developing malaria vaccines (specifically disease caused by Plasmodium vivax) have examined recombinant domain II of AMA-1, which was demonstrated to be immunogenic in mice (25) and a soluble antigen called VMP001 based on the circumsporozoite protein, which was immunogenic in rhesus monkeys (26). A recombinant sub-unit vaccine formulated using a fusion protein between Ag85B and ESAT-6 was shown to be highly protective against Mycobacterium tuberculosis 
135 (the causative agent of tuberculosis) in mice (27). Further examples include development of 136 sub-unit vaccines to protect against dengue virus (28), hepatitis A virus (29), human 137 immunodeficiency virus (30), human rotavirus (31), human respiratory syncytial virus (32), H1N1 influenza virus

Pseudomonas aeruginosa infection (34) and schistosomiasis (35). All these examples use E. coli as the recombinant host and illustrate the importance of this prokaryotic microbe as a tool in vaccine development.

The use of eukaryotic hosts in recombinant protein sub-unit vaccine development: an emerging role for yeasts

While $E$. coli has many benefits as a cell factory, producing a recombinant protein in a prokaryotic host cell can often result in inclusion body formation and/or low specific yields of a product lacking post-translational modification (36). This may be one reason for a general decline in the more recent use of $E$. coli as a host cell and the consequent emergence of several eukaryotic options (5).

In principle, the use of mammalian cell-lines should overcome challenges associated with synthesizing eukaryotic proteins in prokaryotes, especially with recent advances in stable recombinant gene expression $(37,38)$. This is because rates of protein synthesis and folding are almost an order of magnitude faster in prokaryotes than they are in eukaryotes (39), eukaryotic codons are often inefficiently expressed in prokaryotes and authentic eukaryotic post-translational modifications cannot yet be achieved in E. coli (36). In support of this, Synagis ${ }^{\circledR}$, which is used for passive immunization of infants to protect against respiratory syncytial virus, is formulated using a humanized monoclonal antibody (IgG $1_{1 \mathrm{~K}}$; directed against an epitope of the viral F protein) synthesized in mouse myeloma cells (40). In clinical trials, a herpes simplex virus (HSV) vaccine, containing a truncated form of recombinant HSV-2 glycoprotein D from HSV-2 strain G that had been synthesized in Chinese hamster ovary cells, had efficacy in some women dependent on their serologic status, but no efficacy in men (41). 
161 Insect cells have also been used for both commercial vaccine production (Cervarix ${ }^{\circledR}$ and 162 Flublok $^{\circledR}$, Table 1) and in the synthesis of recombinant protein antigens for new vaccine 163 development. For example, the receptor-binding domain of neurotoxin A (rBoNT/A-HC-6h) 164 from Clostridium botulinum was synthesized in insect cells; purified rBoNT/A-HC-6h gave mice full protection against botulinum A toxin with a dose as low as $0.2 \mu \mathrm{g}(42)$. Merozoite surface protein 1 from $P$. falciparum (MSP-1, comprising 43 amino-terminal residues) was also synthesized in insect cells and demonstrated to be immunogenic in rabbits (43). Further examples include development of sub-unit vaccines, some incorporating glycoproteins that would not be possible to synthesize in $E$. coli: these include sub-unit vaccines against chandipura virus (44), hepatitis E virus (45), malaria (specifically disease caused by $P$. falciparum) (46), severe acute respiratory syndrome (SARS) virus (47) and West Nile virus (48).

Plant cells have also been explored as recombinant hosts, with the added possibility of developing edible vaccines. The cholera toxin B subunit, immunoglobulins, $\alpha$-interferon, VP1 protein from foot-and-mouth disease virus and glycoprotein $S$ from transmissible gastroenteritis virus have all been expressed in transgenic plants or by means of plant viruses $(49,50)$. Transgenic tobacco plants (Nicotiana tabacum) have also been used to synthesize a measles virus hemagglutinin (H)

$(H)$ protein that was demonstrated to be immunogenic in mice (51).

Eukaryotic microbes, especially S. cerevisiae and Pichia pastoris offer many of the benefits of higher eukaryotic host cells, whilst retaining the advantages of being microbial. Despite their propensity to hyper-glycosylate recombinant proteins (5), these two yeasts have many advantages: a wealth of molecular and genetic resources are available for both species (52, 53), growth rates are an order of magnitude higher than mammalian cell-lines and they are cheap to culture (54). As discussed above, S. cerevisiae is already used in the manufacture of 12 out of the 16 approved vaccines shown in Table 1; these vaccines are considered safe and efficacious because they are noninfectious and highly immunogenic. 
Table 2 shows examples from the literature suggesting that these advantages are becoming more widely known in academic research laboratories both for $S$. cerevisiae and $P$. pastoris; the latter yeast is a relative new-comer, having been first developed as a recombinant host system in 1985 (55). The PubMed Central database was searched for entries containing "sub-unit" and "vaccine" in any field, which returned 189 articles. This was augmented with searches for entries in any field containing "recombinant" and "vaccine" with the name of the host cell; this returned 266 articles for "pastoris" and 288 entries for "cerevisiae". The articles were examined manually to identify the target disease, the recombinant antigen and the recombinant host cell. Many veterinary vaccines are in development, but only data for potential human recombinant sub-unit vaccines are shown. For S. cerevisiae, several vaccine candidates are based on inactivated whole yeast cells (56) or involve displaying the antigen on the surface of a yeast cell (57), but these are not included in Table 2; only studies using recombinant protein antigens are listed. What is immediately noticeable is the large proportion of very recent studies that have been published using yeast: for S. cerevisiae, 5 out of 12 and for $P$. pastoris 17 out of 21 reports were published between 2010 and 2014 .

\section{Designing improved recombinant antigen synthesis experiments}

In designing any new recombinant protein production strategy, optimization of the gene sequence should be considered so it is more likely to be stably expressed in the chosen recombinant host cell; there is an extensive literature on engineering stabilized proteins (58, 59), while recent insights suggest that codon optimization (60) might aid functional parameters and their interactions on the functional yield of a recombinant protein. In $P$. pastoris cultures, this approach was shown to increase the yield per cell by matching the expression (61). In addition, optimizing culture conditions and induction protocols is essential to increase recombinant protein yields; this has been demonstrated in cultures of both $P$. pastoris $(62,63)$ and E. coli $(64)$. Successful implementation of a "Design of Experiments" approach to bioprocess optimization (65) enables the simultaneous investigation of multiple induction feed profile to the cellular metabolism (66). In a separate study, pulsing $P$. pastoris 
215 cells with an inducer (methanol) revealed the potential benefit of stress in increasing 216 productivity (67). These advances are all easily applicable to recombinant antigen synthesis.

217 S. cerevisiae is particularly amenable to studying the mechanistic basis of high-yielding recombinant protein production experiments using the tools of systems and synthetic biology (68). As stated in a recent review (5), identifying or engineering yeast strains with improved yield characteristics may either be targeted towards one particular pathway or may take a more global approach (69). Examples of the targeted approach include "humanizing" the yeast glycosylation (70) and sterol (71) pathways and modifying membrane phospholipid synthesis to proliferate intracellular membranes (72). Studies taking a more global approach in both $S$. cerevisiae $(73,74)$ and $P$. pastoris $(62,75)$ have identified the importance of the unfolded protein response (the cellular stress response activated by the accumulation of unfolded or misfolded protein) and reduced translational activity in high yielding cultures. Such insights, which are not yet possible in higher eukaryotic systems, have been used to select specific yeast strains that can substantially improve recombinant protein yields compared to wild-type cells $(76,77)$.

\section{Conclusions}

E. coli is often the first host cell to be considered in the synthesis of a new recombinant protein, although the commercial production of approved sub-unit vaccines relies on $S$. cerevisiae and insect cells as well as E. coli (Table 1). Table 2 illustrates the use of yeast as a research tool in vaccine development. This is particularly notable for $P$. pastoris, which has become a popular host very recently. Using both prokaryotic and eukaryotic microbes makes practical sense, since working with bacteria and yeast require similar techniques, equipment and approaches. Yeasts should therefore be considered alongside E. coli in developing a strategy to produce recombinant protein sub-unit vaccines, especially those based on VLPS, or as a tool to screen novel antigens in new vaccine development. 
Lindsay Marshall, Professor Yvonne Perrie and Alan Taylor, for critical comments on the

manuscript.

\section{References}

1. C.M. Kao, R.J. Schneyer, and J.A. Bocchini, Jr. Child and adolescent immunizations: selected review of recent US recommendations and literature. Curr Opin Pediatr (2014).

2. S. Liljeqvistand S. Stahl. Production of recombinant subunit vaccines: protein immunogens, live delivery systems and nucleic acid vaccines. Journal of biotechnology. 73:1-33 (1999).

3. R.L. Coffman, A. Sher, and R.A. Seder. Vaccine adjuvants: putting innate immunity to work. Immunity. 33:492-503 (2010).

4. S.A. Plotkin. Vaccines: past, present and future. Nat Med. 11:S5-11 (2005).

5. R.M. Bill. Playing catch-up with Escherichia coli: using yeast to increase success rates in recombinant protein production experiments. Front Microbiol. 5:85 (2014).

6. M.D. Spring, J.F. Cummings, C.F. Ockenhouse, S. Dutta, R. Reidler, E. Angov, E. Bergmann-Leitner, V.A. Stewart, S. Bittner, L. Juompan, M.G. Kortepeter, R. Nielsen, U. Krzych, E. Tierney, L.A. Ware, M. Dowler, C.C. Hermsen, R.W. Sauerwein, S.J. de Vlas, O. Ofori-Anyinam, D.E. Lanar, J.L. Williams, K.E. Kester, K. Tucker, M. Shi, E. Malkin, C. Long, C.L. Diggs, L. Soisson, M.C. Dubois, W.R. Ballou, J. Cohen, and D.G. Heppner, Jr. Phase $1 / 2$ a study of the malaria vaccine candidate apical membrane antigen-1 (AMA-1) administered in adjuvant system AS01B or AS02A. PLoS One. 4:e5254 (2009).

7. A. Roldao, M.C. Mellado, L.R. Castilho, M.J. Carrondo, and P.M. Alves. Virus-like particles in vaccine development. Expert review of vaccines. 9:1149-1176 (2010).

8. S.J. Peacock, D. Limmathurotsakul, Y. Lubell, G.C. Koh, L.J. White, N.P. Day, and R.W. Titball. Melioidosis vaccines: a systematic review and appraisal of the potential to exploit biodefense vaccines for public health purposes. PLoS Negl Trop Dis. 6:e1488 (2012).

9. S.N. Cohen, A.C. Chang, H.W. Boyer, and R.B. Helling. Construction of biologically functional bacterial plasmids in vitro. Proceedings of the National Academy of Sciences of the United States of America. 70:3240-3244 (1973).

10. K. Itakura, T. Hirose, R. Crea, A.D. Riggs, H.L. Heyneker, F. Bolivar, and H.W. Boyer. Expression in Escherichia coli of a chemically synthesized gene for the hormone somatostatin. Science. 198:1056-1063 (1977).

11. D.V. Goeddel, D.G. Kleid, F. Bolivar, H.L. Heyneker, D.G. Yansura, R. Crea, T. Hirose, A. Kraszewski, K. Itakura, and A.D. Riggs. Expression in Escherichia coli of chemically synthesized genes for human insulin. Proceedings of the National Academy of Sciences of the United States of America. 76:106-110 (1979).

12. M. Goodman. Market watch: Sales of biologics to show robust growth through to 2013. Nat Rev Drug Discov. 8:837 (2009).

13. N. Ferrer-Miralles, J. Domingo-Espin, J.L. Corchero, E. Vazquez, and A. Villaverde. Microbial factories for recombinant pharmaceuticals. Microbial cell factories. 8:17 (2009).

14. J. Zhu. Mammalian cell protein expression for biopharmaceutical production. Biotechnol Adv. 30:1158-1170 (2012).

15. D. Mattanovich, P. Branduardi, L. Dato, B. Gasser, M. Sauer, and D. Porro. Recombinant protein production in yeasts. Methods Mol Biol. 824:329-358 (2012). 
16. P. Valenzuela, A. Medina, W.J. Rutter, G. Ammerer, and B.D. Hall. Synthesis and assembly of hepatitis B virus surface antigen particles in yeast. Nature. 298:347-350 (1982).

17. L.E. Nigrovicand K.M. Thompson. The Lyme vaccine: a cautionary tale. Epidemiol Infect. 135:1-8 (2007).

18. M.I. Meltzer, D.T. Dennis, and K.A. Orloski. The cost effectiveness of vaccinating against Lyme disease. Emerg Infect Dis. 5:321-328 (1999).

19. A. Soliakov, I.F. Kelly, J.H. Lakey, and A. Watkinson. Anthrax sub-unit vaccine: the structural consequences of binding rPA83 to Alhydrogel(R). Eur J Pharm Biopharm. 80:25-32 (2012).

20. S.M. Jones, F. Day, A.J. Stagg, and E.D. Williamson. Protection conferred by a fully recombinant sub-unit vaccine against Yersinia pestis in male and female mice of four inbred strains. Vaccine. 19:358-366 (2000).

21. J.L. Holley, M. Elmore, M. Mauchline, N. Minton, and R.W. Titball. Cloning, expression and evaluation of a recombinant sub-unit vaccine against Clostridium botulinum type F toxin. Vaccine. 19:288-297 (2000).

22. H. Kleanthous, C.K. Lee, and T.P. Monath. Vaccine development against infection with Helicobacter pylori. Br Med Bull. 54:229-241 (1998).

23. C. Colonna, R. Dorati, B. Conti, P. Caliceti, and I. Genta. Sub-unit vaccine against S. aureus-mediated infections: set-up of nano-sized polymeric adjuvant. Int J Pharm. 452:390-401 (2013).

24. M.S. Duthie, L.H. Sampaio, R.M. Oliveira, V.S. Raman, J. O'Donnell, H.R. Bailor, G.C. Ireton, A.L. Sousa, M.M. Stefani, and S.G. Reed. Development and pre-clinical assessment of a $73 \mathrm{kD}$ chimeric fusion protein as a defined sub-unit vaccine for leprosy. Vaccine. 31:813-819 (2013).

25. B.C. Mufalo, F. Gentil, D.Y. Bargieri, F.T. Costa, M.M. Rodrigues, and I.S. Soares. Plasmodium vivax apical membrane antigen-1: comparative recognition of different domains by antibodies induced during natural human infection. Microbes Infect. 10:1266-1273 (2008).

26. Y. Vanloubbeeck, S. Pichyangkul, B. Bayat, K. Yongvanitchit, J.W. Bennett, J. Sattabongkot, K. Schaecher, C.F. Ockenhouse, J. Cohen, A. Yadava, and P. vivax vaccine study group. Comparison of the immune responses induced by soluble and particulate Plasmodium vivax circumsporozoite vaccine candidates formulated in AS01 in rhesus macaques. Vaccine. 31:6216-6224 (2013).

27. A. Weinrich Olsen, L.A. van Pinxteren, L. Meng Okkels, P. Birk Rasmussen, and P. Andersen. Protection of mice with a tuberculosis subunit vaccine based on a fusion protein of antigen 85b and esat-6. Infection and immunity. 69:2773-2778 (2001).

28. R. Ramirez, R. Falcon, A. Izquierdo, A. Garcia, M. Alvarez, A.B. Perez, Y. Soto, M. Mune, E.M. da Silva, O. Ortega, R. Mohana-Borges, and M.G. Guzman.

Recombinant dengue 2 virus NS3 protein conserves structural antigenic and immunological properties relevant for dengue vaccine design. Virus genes (2014).

29. K.O. Jang, J.H. Park, H.H. Lee, D.K. Chung, W. Kim, and I.S. Chung. Expression and immunogenic analysis of recombinant polypeptides derived from capsid protein VP1 for developing subunit vaccine material against hepatitis A virus. Protein expression and purification. 100C:1-9 (2014).

30. K. Wu, X. Xue, M. Li, X. Qin, C. Zhang, W. Li, Q. Hao, Z. Wang, Q. Liu, W. Zhang, and $Y$. Zhang. High level expression, purification and characterization of recombinant CCR5 as a vaccine candidate against HIV. Protein expression and purification. 89:124-130 (2013).

31. X. Wen, D. Cao, R.W. Jones, J. Li, S. Szu, and Y. Hoshino. Construction and characterization of human rotavirus recombinant VP8* subunit parenteral vaccine candidates. Vaccine. 30:6121-6126 (2012).

32. N. Dagouassat, V. Robillard, J.F. Haeuw, H. Plotnicky-Gilquin, U.F. Power, N. Corvaia, T. Nguyen, J.Y. Bonnefoy, and A. Beck. A novel bipolar mode of attachment 
to aluminium-containing adjuvants by BBG2Na, a recombinant subunit hRSV vaccine. Vaccine. 19:4143-4152 (2001).

33. J.J. Treanor, D.N. Taylor, L. Tussey, C. Hay, C. Nolan, T. Fitzgerald, G. Liu, U. Kavita, L. Song, I. Dark, and A. Shaw. Safety and immunogenicity of a recombinant hemagglutinin influenza-flagellin fusion vaccine (VAX125) in healthy young adults. Vaccine. 28:8268-8274 (2010).

34. A. Tanomand, S. Farajnia, S. Najar Peerayeh, and J. Majidi. Cloning, expression and characterization of recombinant exotoxin A-flagellin fusion protein as a new vaccine candidate against Pseudomonas aeruginosa infections. Iranian biomedical journal. 17:1-7 (2013).

35. R.M. Chura-Chambi, E. Nakajima, R.R. de Carvalho, P.A. Miyasato, S.C. Oliveira, L. Morganti, and E.A. Martins. Refolding of the recombinant protein Sm29, a step toward the production of the vaccine candidate against schistosomiasis. Journal of biotechnology. 168:511-519 (2013).

36. H.P. Sørensen. Towards universal systems for recombinant gene expression. Microbial cell factories. 9:27 (2010).

37. A.D. Bandaranayakeand S.C. Almo. Recent advances in mammalian protein production. FEBS Letters (2013).

38. R. Kunertand E. Casanova. Recent advances in recombinant protein production: BAC-based expression vectors, the bigger the better. Bioengineered. 4:258-261 (2013).

39. M. Widmannand P. Christen. Comparison of folding rates of homologous prokaryotic and eukaryotic proteins. J Biol Chem. 275:18619-18622 (2000).

40. D. Null, Jr., B. Pollara, P.H. Dennehy, J. Steichen, P.J. Sanchez, L.B. Givner, D. Carlin, B. Landry, F.H. Top, Jr., and E. Connor. Safety and immunogenicity of palivizumab (Synagis) administered for two seasons. The Pediatric infectious disease journal. 24:1021-1023 (2005).

41. L.R. Stanberry, S.L. Spruance, A.L. Cunningham, D.I. Bernstein, A. Mindel, S. Sacks, S. Tyring, F.Y. Aoki, M. Slaoui, M. Denis, P. Vandepapeliere, and G. Dubin. Glycoprotein-D-adjuvant vaccine to prevent genital herpes. N Engl J Med. 347:16521661 (2002).

42. O.B. Villaflores, C.M. Hsei, C.Y. Teng, Y.J. Chen, J.J. Wey, P.Y. Tsui, R.H. Shyu, K.L. Tung, J.M. Yeh, D.J. Chiao, and T.Y. Wu. Easy expression of the C-terminal heavy chain domain of botulinum neurotoxin serotype $A$ as a vaccine candidate using a bi-cistronic baculovirus system. Journal of virological methods. 189:58-64 (2013).

43. D.E. Arnot, D.R. Cavanagh, E.J. Remarque, A.M. Creasey, M.P. Sowa, W.D. Morgan, A.A. Holder, S. Longacre, and A.W. Thomas. Comparative testing of six antigen-based malaria vaccine candidates directed toward merozoite-stage Plasmodium falciparum. Clin Vaccine Immunol. 15:1345-1355 (2008).

44. C.H. Venkateswarluand V.A. Arankalle. Recombinant glycoprotein based vaccine for Chandipura virus infection. Vaccine. 27:2845-2850 (2009).

45. C.P. McAtee, Y. Zhang, P.O. Yarbough, T.R. Fuerst, K.L. Stone, S. Samander, and K.R. Williams. Purification and characterization of a recombinant hepatitis $E$ protein vaccine candidate by liquid chromatography-mass spectrometry. Journal of chromatography B, Biomedical applications. 685:91-104 (1996).

46. Y.P. Shi, S.E. Hasnain, J.B. Sacci, B.P. Holloway, H. Fujioka, N. Kumar, R. Wohlhueter, S.L. Hoffman, W.E. Collins, and A.A. Lal. Immunogenicity and in vitro protective efficacy of a recombinant multistage Plasmodium falciparum candidate vaccine. Proceedings of the National Academy of Sciences of the United States of America. 96:1615-1620 (1999).

47. Z. Zhou, P. Post, R. Chubet, K. Holtz, C. McPherson, M. Petric, and M. Cox. A recombinant baculovirus-expressed $S$ glycoprotein vaccine elicits high titers of SARS-associated coronavirus (SARS-CoV) neutralizing antibodies in mice. Vaccine. 24:3624-3631 (2006). 
48. N. Bonafe, J.A. Rininger, R.G. Chubet, H.G. Foellmer, S. Fader, J.F. Anderson, S.L. Bushmich, K. Anthony, M. Ledizet, E. Fikrig, R.A. Koski, and P. Kaplan. A recombinant West Nile virus envelope protein vaccine candidate produced in Spodoptera frugiperda expresSF+ cells. Vaccine. 27:213-222 (2009).

49. J.K. Ma, P.M. Drake, and P. Christou. The production of recombinant pharmaceutical proteins in plants. Nature reviews Genetics. 4:794-805 (2003).

50. S.J. Streatfieldand J.A. Howard. Plant-based vaccines. International journal for parasitology. 33:479-493 (2003).

51. Z. Huang, I. Dry, D. Webster, R. Strugnell, and S. Wesselingh. Plant-derived measles virus hemagglutinin protein induces neutralizing antibodies in mice. Vaccine. 19:2163-2171 (2001).

52. K. De Schutter, Y.C. Lin, P. Tiels, A. Van Hecke, S. Glinka, J. Weber-Lehmann, P. Rouze, Y. Van de Peer, and N. Callewaert. Genome sequence of the recombinant protein production host Pichia pastoris. Nat Biotechnol. 27:561-566 (2009).

53. A. Goffeau, B.G. Barrell, H. Bussey, R.W. Davis, B. Dujon, H. Feldmann, F. Galibert, J.D. Hoheisel, C. Jacq, M. Johnston, E.J. Louis, H.W. Mewes, Y. Murakami, P. Philippsen, H. Tettelin, and S.G. Oliver. Life with 6000 genes. Science. 274:546, 563547 (1996).

54. D. Porro, B. Gasser, T. Fossati, M. Maurer, P. Branduardi, M. Sauer, and D. Mattanovich. Production of recombinant proteins and metabolites in yeasts: when are these systems better than bacterial production systems? Applied microbiology and biotechnology. 89:939-948 (2011).

55. J.M. Cregg, K.J. Barringer, A.Y. Hessler, and K.R. Madden. Pichia pastoris as a host system for transformations. Mol Cell Biol. 5:3376-3385 (1985).

56. F. Habersetzer, T.F. Baumert, and F. Stoll-Keller. GI-5005, a yeast vector vaccine expressing an NS3-core fusion protein for chronic HCV infection. Current opinion in molecular therapeutics. 11:456-462 (2009).

57. B. Upadhyayaand R. Manjunath. Baker's yeast expressing the Japanese encephalitis virus envelope protein on its cell surface: induction of an antigen-specific but nonneutralizing antibody response. Yeast. 26:383-397 (2009).

58. D.J. Scott, L. Kummer, D. Tremmel, and A. Pluckthun. Stabilizing membrane proteins through protein engineering. Curr Opin Chem Biol. 17:427-435 (2013).

59. M.W. Traxlmayrand C. Obinger. Directed evolution of proteins for increased stability and expression using yeast display. Arch Biochem Biophys. 526:174-180 (2012).

60. F. Oberg, J. Sjohamn, M.T. Conner, R.M. Bill, and K. Hedfalk. Improving recombinant eukaryotic membrane protein yields in Pichia pastoris: the importance of codon optimization and clone selection. Mol Membr Biol. 28:398-411 (2011).

61. M. Hallidayand G.R. Mallucci. Targeting the unfolded protein response in neurodegeneration: A new approach to therapy. Neuropharmacology. 76 Pt A:169174 (2014).

62. C. Rebnegger, A.B. Graf, M. Valli, M.G. Steiger, B. Gasser, M. Maurer, and D. Mattanovich. In Pichia pastoris, growth rate regulates protein synthesis and secretion, mating and stress response. Biotechnol J (2013).

63. O. Spadiut, D. Zalai, C. Dietzsch, and C. Herwig. Quantitative comparison of dynamic physiological feeding profiles for recombinant protein production with Pichia pastoris. Bioprocess Biosyst Eng (2013).

64. M. Jaziniand C. Herwig. Effects of temperature shifts and oscillations on recombinant protein production expressed in Escherichia coli. Bioprocess Biosyst Eng. 36:15711577 (2013).

65. N. Bora, Z. Bawa, R.M. Bill, and M.D. Wilks. The implementation of a design of experiments strategy to increase recombinant protein yields in yeast (review). Methods Mol Biol. 866:115-127 (2012).

66. W.J. Holmes, R.A. Darby, M.D. Wilks, R. Smith, and R.M. Bill. Developing a scalable model of recombinant protein yield from Pichia pastoris: the influence of culture conditions, biomass and induction regime. Microbial cell factories. 8:35 (2009). 
67. C. Dietzsch, O. Spadiut, and C. Herwig. A dynamic method based on the specific substrate uptake rate to set up a feeding strategy for Pichia pastoris. Microbial cell factories. 10:14 (2011).

68. D. Drew, S. Newstead, Y. Sonoda, H. Kim, G. von Heijne, and S. Iwata. GFP-based optimization scheme for the overexpression and purification of eukaryotic membrane proteins in Saccharomyces cerevisiae. Nat Protoc. 3:784-798 (2008).

69. M.P. Ashe and R.M. Bill. Mapping the yeast host cell response to recombinant membrane protein production: relieving the biological bottlenecks. Biotechnol J. 6:707-714 (2011).

70. K. De Pourcq, K. De Schutter, and N. Callewaert. Engineering of glycosylation in yeast and other fungi: current state and perspectives. Applied microbiology and biotechnology. 87:1617-1631 (2010).

71. S.M. Kitson, W. Mullen, R.J. Cogdell, R.M. Bill, and N.J. Fraser. GPCR production in a novel yeast strain that makes cholesterol-like sterols. Methods. 55:287-292 (2011).

72. M. Guerfal, K. Claes, O. Knittelfelder, R. De Rycke, S.D. Kohlwein, and N. Callewaert. Enhanced membrane protein expression by engineering increased intracellular membrane production. Microbial cell factories. 12:122 (2013).

73. N. Bonanderand R.M. Bill. Relieving the first bottleneck in the drug discovery pipeline: using array technologies to rationalize membrane protein production. Expert Rev Proteomics. 6:501-505 (2009).

74. N. Bonander, K. Hedfalk, C. Larsson, P. Mostad, C. Chang, L. Gustafsson, and R.M. Bill. Design of improved membrane protein production experiments: quantitation of the host response. Protein Sci. 14:1729-1740 (2005).

75. K. Baumann, N. Adelantado, C. Lang, D. Mattanovich, and P. Ferrer. Protein trafficking, ergosterol biosynthesis and membrane physics impact recombinant protein secretion in Pichia pastoris. Microbial cell factories. 10:93 (2011).

76. N. Bonander, R.A. Darby, L. Grgic, N. Bora, J. Wen, S. Brogna, D.R. Poyner, M.A. O'Neill, and R.M. Bill. Altering the ribosomal subunit ratio in yeast maximizes recombinant protein yield. Microbial cell factories. 8:10 (2009).

77. K. Norden, M. Agemark, J.A. Danielson, E. Alexandersson, P. Kjellbom, and U. Johanson. Increasing gene dosage greatly enhances recombinant expression of aquaporins in Pichia pastoris. BMC Biotechnol. 11:47 (2011).

78. R.W. Hepler, R. Kelly, T.B. McNeely, H. Fan, M.C. Losada, H.A. George, A. Woods, L.D. Cope, A. Bansal, J.C. Cook, G. Zang, S.L. Cohen, X. Wei, P.M. Keller, E. Leffel, J.G. Joyce, L. Pitt, L.D. Schultz, K.U. Jansen, and M. Kurtz. A recombinant 63-kDa form of Bacillus anthracis protective antigen produced in the yeast Saccharomyces cerevisiae provides protection in rabbit and primate inhalational challenge models of anthrax infection. Vaccine. 24:1501-1514 (2006).

79. M.A. Romanos, A.J. Makoff, N.F. Fairweather, K.M. Beesley, D.E. Slater, F.B. Rayment, M.M. Payne, and J.J. Clare. Expression of tetanus toxin fragment $C$ in yeast: gene synthesis is required to eliminate fortuitous polyadenylation sites in ATrich DNA. Nucleic acids research. 19:1461-1467 (1991).

80. N.L. Nguyen, J.M. Kim, J.A. Park, S.M. Park, Y.S. Jang, M.S. Yang, and D.H. Kim. Expression and purification of an immunogenic dengue virus epitope using a synthetic consensus sequence of envelope domain III and Saccharomyces cerevisiae. Protein expression and purification. 88:235-242 (2013).

81. L. Antoniukas, H. Grammel, and U. Reichl. Production of hantavirus Puumala nucleocapsid protein in Saccharomyces cerevisiae for vaccine and diagnostics. Journal of biotechnology. 124:347-362 (2006).

82. N. Tomo, T. Goto, and Y. Morikawa. Trans-packaging of human immunodeficiency virus type 1 genome into Gag virus-like particles in Saccharomyces cerevisiae. Microbial cell factories. 12:28 (2013).

83. O. Mendoza-Vega, E. Keppi, B. Bouchon, M. Nguyen, and T. Achstetter. Recombinant outer-surface protein A (des-Cys1-OspA) from the Lyme disease 
spirochete Borrelia burgdorferi: high production levels in Saccharomyces cerevisiae yeast cultures. Applied microbiology and biotechnology. 44:624-628 (1996).

84. N.J. Schuldtand A. Amalfitano. Malaria vaccines: focus on adenovirus based vectors. Vaccine. 30:5191-5198 (2012).

85. M.M. Gozar, V.L. Price, and D.C. Kaslow. Saccharomyces cerevisiae-secreted fusion proteins Pfs25 and Pfs28 elicit potent Plasmodium falciparum transmission-blocking antibodies in mice. Infection and immunity. 66:59-64 (1998).

86. B. Rombautand J.P. Jore. Immunogenic, non-infectious polio subviral particles synthesized in Saccharomyces cerevisiae. The Journal of general virology. 78 ( Pt 8):1829-1832 (1997).

87. S.R. Klepfer, C. Debouck, J. Uffelman, P. Jacobs, A. Bollen, and E.V. Jones. Characterization of rabies glycoprotein expressed in yeast. Archives of virology. 128:269-286 (1993).

88. W.A. Rodriguez-Limas, K.E. Tyo, J. Nielsen, O.T. Ramirez, and L.A. Palomares. Molecular and process design for rotavirus-like particle production in Saccharomyces cerevisiae. Microbial cell factories. 10:33 (2011).

89. L. Tan, H. Wang, X. Tan, J. Zou, and Z. Yao. Yeast expressed foldable quadrivalent Abeta15 elicited strong immune response against Abeta without Abeta-specific $T$ cell response in wild C57BL/6 mice. Hum Vaccin Immunother. 8:1090-1098 (2012).

90. G.H. Fontanella, K. De Vusser, W. Laroy, L. Daurelio, A.L. Nocito, S. Revelli, and R. Contreras. Immunization with an engineered mutant trans-sialidase highly protects mice from experimental Trypanosoma cruzi infection: a vaccine candidate. Vaccine. 26:2322-2334 (2008).

91. G. Batra, C. Gurramkonda, S.K. Nemani, S.K. Jain, S. Swaminathan, and N. Khanna. Optimization of conditions for secretion of dengue virus type 2 envelope domain III using Pichia pastoris. J Biosci Bioeng. 110:408-414 (2010).

92. M. Wang, S. Jiang, X. Liu, and Y. Wang. Expression, purification, and immunogenic characterization of Epstein-Barr virus recombinant EBNA1 protein in Pichia pastoris. Applied microbiology and biotechnology. 97:6251-6262 (2013).

93. M. Wang, S. Jiang, and Y. Wang. Recombinant VP1 protein expressed in Pichia pastoris induces protective immune responses against EV71 in mice. Biochem Biophys Res Commun. 430:387-393 (2013).

94. A.A. O'Riordan, V.A. Morales, L. Mulligan, N. Faheem, H.J. Windle, and D.P. Kelleher. Alkyl hydroperoxide reductase: a candidate Helicobacter pylori vaccine. Vaccine. 30:3876-3884 (2012).

95. C. Gurramkonda, M. Zahid, S.K. Nemani, A. Adnan, S.K. Gudi, N. Khanna, T. Ebensen, H. Lunsdorf, C.A. Guzman, and U. Rinas. Purification of hepatitis B surface antigen virus-like particles from recombinant Pichia pastoris and in vivo analysis of their immunogenic properties. J Chromatogr B Analyt Technol Biomed Life Sci. 940:104-111 (2013).

96. W. Cai, L. Su, Q. Liao, L. Ye, Y. Wu, Z. Wu, and Y. She. Expression, purification and immunogenic characterization of hepatitis $C$ virus recombinant E1E2 protein expressed by Pichia pastoris yeast. Antiviral Res. 88:80-85 (2010).

97. E. Curti, C.A. Seid, E. Hudspeth, L. Center, W. Rezende, J. Pollet, C. Kwityn, M. Hammond, R.K. Matsunami, D.A. Engler, P.J. Hotez, and M. Elena Bottazzi. Optimization and revisions of the production process of the Necator americanus glutathione S-transferase 1 (Na-GST-1), the lead hookworm vaccine recombinant protein candidate. Hum Vaccin Immunother. 10: (2014).

98. W.Z. Jiang, N.Y. Jin, Z.J. Li, L.S. Zhang, H.W. Wang, Y.J. Zhang, and W.Y. Han. Expression and characterization of Gag protein of HIV-1(CN) in Pichia pastoris. Journal of virological methods. 123:35-40 (2005).

99. E.C. Coimbra, F.B. Gomes, J.F. Campos, M. D'Arc, J.C. Carvalho, F.C. Mariz, A.L. Jesus, R.C. Stocco, W. Becak, and A.C. Freitas. Production of L1 protein from different types of HPV in Pichia pastoris using an integrative vector. Braz J Med Biol Res. 44:1209-1214 (2011). 
100. E. Curti, C. Kwityn, B. Zhan, P. Gillespie, J. Brelsford, V. Deumic, J. Plieskatt, W.C. Rezende, E. Tsao, B. Kalampanayil, P.J. Hotez, and M.E. Bottazzi. Expression at a $20 \mathrm{~L}$ scale and purification of the extracellular domain of the Schistosoma mansoni TSP-2 recombinant protein: A vaccine candidate for human intestinal schistosomiasis. Hum Vaccin Immunother. 9: (2013).

101. M. Subathra, P. Santhakumar, M.L. Narasu, S.S. Beevi, and S.K. Lal. Evaluation of antibody response in mice against avian influenza $A(H 5 N 1)$ strain neuraminidase expressed in yeast Pichia pastoris. J Biosci. 39:443-451 (2014).

102. T.N. Athmaram, A.K. Singh, S. Saraswat, S. Srivastava, P. Misra, M. Kameswara Rao, N. Gopalan, and P.V. Rao. A simple Pichia pastoris fermentation and downstream processing strategy for making recombinant pandemic Swine Origin Influenza a virus Hemagglutinin protein. J Ind Microbiol Biotechnol. 40:245-255 (2013).

103. W.T. Kwon, W.S. Lee, P.J. Park, T.K. Park, and H. Kang. Protective immunity of Pichia pastoris-expressed recombinant envelope protein of Japanese encephalitis virus. J Microbiol Biotechnol. 22:1580-1587 (2012).

104. Y.L. Lau, G. Thiruvengadam, W.W. Lee, and M.Y. Fong. Immunogenic characterization of the chimeric surface antigen 1 and 2 (SAG1/2) of Toxoplasma gondii expressed in the yeast Pichia pastoris. Parasitol Res. 109:871-878 (2011).

105. D. Jacob, C. Ruffie, M. Dubois, C. Combredet, R. Amino, P. Formaglio, O. Gorgette, G. Pehau-Arnaudet, C. Guery, O. Puijalon, J.C. Barale, R. Menard, F. Tangy, and M. Sala. Whole Pichia pastoris yeast expressing measles virus nucleoprotein as a production and delivery system to multimerize Plasmodium antigens. PLoS One. 9:e86658 (2014).

106. E.C. Vicentin, K.S. Francoso, M.V. Rocha, D. Iourtov, F.L. Dos Santos, F.S. Kubrusly, M.A. Sakauchi, I. Raw, F. Nosten, L. Renia, M.M. Rodrigues, B. Russell, and I.S. Soares. Invasion-inhibitory antibodies elicited by immunization with Plasmodium vivax apical membrane antigen-1 expressed in Pichia pastoris yeast. Infection and immunity. 82:1296-1307 (2014).

107. M. Xia, T. Farkas, and X. Jiang. Norovirus capsid protein expressed in yeast forms virus-like particles and stimulates systemic and mucosal immunity in mice following an oral administration of raw yeast extracts. Journal of medical virology. 79:74-83 (2007). 
Table 1. Recombinant protein sub-unit vaccines approved for human use. Sub-unit vaccines containing a recombinant protein antigen that have been approved for human use in the United States of America (US) or the European Union (EU) are listed in order of the date on which they were approved. Data were retrieved on $28^{\text {th }}$ May 2014 from the FDA

(http://www.fda.gov/BiologicsBloodVaccines/Vaccines/ApprovedProducts/ucm093830.htm), EMA

(http://www.ema.europa.eu/ema/index.jsp?curl=pages/includes/medicines/medicines_landing_page.jsp\&mid=) and the United Kingdom Department of Health (https://www.gov.uk/government/collections/immunisation-against-infectious-disease-the-green-book) websites. While 14 out of 16 vaccine formulations contain antigens synthesized in microbes, only two distinct antigens are synthesized in Saccharomyces cerevisiae and a further two in Escherichia coli. Insect cells are used to synthesize two additional distinct antigens.

\section{Recombinant \\ host}

Escherichia coli Lymerix $^{\circledR}$

Bexsero $^{\circledR}$

Neisseria meningitides

(causative agent of

meningococcal meningitis and septicemia)

Borrelia burgdorferi (causative agent of Lyme disease in US)

Recombinant antigen

Manufacturer

Saccharomyces cerevisiae

Recombivax- Hepatitis B virus $\mathrm{HB}^{\circledR}$

Comvax ${ }^{\circledR}$

Hepatitis B virus and

Haemophilus influenzae type $B$ causative agent of pneumonia or meningitis, especially in young children

Tritanrix-HB ${ }^{\circledR} \quad$ Hepatitis B virus,
OspA lipoprotein

GlaxoSmithKline Biologicals

Factor $\mathrm{H}$ binding protein (fHbp), Neisserial adhesin A

$(\operatorname{NadA})$, Neisseria heparin binding antigen (NHBA) and

Porin A (PorA) from

meningococcal strain NZ $98 / 254$
Hepatitis B surface antigen (HBsAg)

HBsAg

Merck \& Co Inc

1986 (US)

Merck \& Co Inc

1996 (US)
1998 (US); vaccine withdrawn by

GlaxoSmithKline

Biologicals in 2002

2013 (EU)

Novartis

HBsAg
GlaxoSmithKline 
Corynebacterium diphtheria

(causative agent of

diptheria), Clostridium tetani

(causative agent of tetanus) and

Bordetella pertussis (causative

agent of whooping cough)
Twinrix $^{\circledR}$

Engerix-B ${ }^{\circledR}$

Primavax $^{\circledR}$

Procomvax $^{\circledR}$

Hepatitis $B$ virus and $H$.

influenzae type B

\section{HBvaxPRO ${ }^{\circledR} \quad$ Hepatitis B virus \\ Hepatitis B virus, $C$ \\ diphtheria, C. tetani, $B$ \\ pertussis and poliovirus \\ Pediarix $^{\circledR}$}

Ambirix ${ }^{\circledR} \quad$ Hepatitis A and $B$ viruses

HBsAg

Fendrix $^{\circledR}$

HBsAg

HBsAg

HBsAg

$$
\text { Hepatitis A and B viruses }
$$

HBsAg
Biologicals

\section{withdrawn by}

GlaxoSmithKline

Biologicals in 2009

GlaxoSmithKline
Biologicals

GlaxoSmithKline

Biologicals

Sanofi Pasteur

MSD

1996 (EU; adult vaccine); 1997 (EU; paediatric vaccine)

1998 (US)

1998 (EU); vaccine withdrawn by Sanofi Pasteur MSD in 2000

Sanofi Pasteur MSD

1999 (EU); vaccine withdrawn by Sanofi Pasteur MSD in 2009

Sanofi Pasteur

2001 (EU)

MSD

GlaxoSmithKline 2002 (US) Biologicals

GlaxoSmithKline 2002 (EU) Biologicals

GlaxoSmithKline 2005 (EU) 
Biologicals

Gardasil Human papillomavirus

Insect cells
Cervarix ${ }^{\circledR} \quad$ Human papillomavirus

Flublok $^{\circledR}$

Influenza virus
Major capsid protein, L1, for human papillomavirus types 6

11,16 and 18

Major capsid protein, L1, for human papillomavirus types 16 and 18

Full-length hemagglutinin (influenza virus A strains, $\mathrm{H} 1 \mathrm{~N} 1$ and $\mathrm{H} 3 \mathrm{~N} 2$, and one influenza virus B strain)
Merck \& Co Inc

2006 (US)

Sanofi Pasteur MSD

GlaxoSmithKline

Biologicals 2009 (US)

Protein Sciences 2013 (US)

$2006(E U)$

Corporation 
Table 2. Examples of recombinant protein antigens synthesized in yeast for use in developing human sub-unit vaccines. Antigens synthesized in S. cerevisiae or $P$. pastoris are listed alphabetically by the relevant disease. The PubMed Central database was searched for entries containing "sub-unit" and "vaccine" in any field, which returned 189 articles. This was augmented with searches for entries in any field containing "recombinant" and "vaccine" with the name of the host cell; this returned 266 articles for "pastoris" and 288 entries for "cerevisiae". These articles were examined manually to identify the target disease, the antigen and the recombinant host cell. Many veterinary vaccines are 609 These articles were examined manually to identify the target disease, the antigen and the reco

\section{Recombinant}

host

\section{Disease \\ (causative \\ organism)}

Saccharomyces Anthrax

cerevisiae
(Bacillus anthracis)

Tetanus

(Clostridium tetani)

Dengue virus

Hantavirus

Human

immunodeficiency

virus type 1

Lyme disease

(Borrelia

burgdorferi)

Malaria

(Plasmodium spp)

\section{Antigen}

Protective antigen component of the anthrax toxin complex, PA63

Tetanus toxin fragment $\mathrm{C}$

Dengue envelope domain III (scEDIII) from all four serotypes

Hantavirus N protein

Gag protein

$\mathrm{N}$-terminally truncated form of outer-surface protein A (des-Cys1-OspA)

RTS,S that consists of sequences of the circumsporozoite protein and the hepatitis B surface antigen (HBsAg). RTS and S spontaneously assemble into mixed
Outcome

Reference

Protection against infection was demonstrated in rabbits and non-human primates

Protection against infection was demonstrated in mice

Immunogenicity was demonstrated in mice

Mid-scale $(5 \mathrm{~L})$ production demonstrated

Spheroplasts released Gag virus-like particles extracellularly

Improved yields over synthesis in E. coli

Vaccine is in phase 3 clinical trials; it induced protection in $56 \%$ of vaccinees 
polymeric particulate structures. These VLPsare each estimated to contain, on average, 100 polypeptides

Malaria

(Plasmodium

falciparum

Malaria

(Plasmodium vivax)

comprises CSV-S (a fusion protein between a soluble form of CSV and HBsAg) and free HBsAg co-expressed in yeast and selfassembled into mixed VLPS

Poliovirus

$\mathrm{P} 1$, the precursor for the structural proteins and $3 C D$, the viral protease

Rabies virus

Rabies virus surface glycoprotein

Structural proteins VP2, VP6 and VP7

Rotavirus

Alzheimer's

disease

Chagas' disease

(Trypanosoma

cruzi)

Dengue virus

Recombinant $4 \times A \beta 15$, four tandem repeats of amyloid $\beta(1-15)$ interlinked by spacers

Trans-sialidase containing the catalytic (Shed Acute Phase Antigen) repeats Dengue virus type 2 envelope domain III
A particulate antigen called CSV-S,S based

on the circumsporozoite (CSV) protein. It

Sexual-stage surface antigens synthesized as a Pfs25-28 fusion protein

Pfs25-28 elicits potent $P$. falciparum

transmission-blocking antibodies in mice.

The particulate antigen was immunogenic

in rhesus monkeys

Protective following intramuscular injection in guinea pigs

Production of triple-layered rotavirus VLP demonstrated

Proposed as an alternative to previous human clinical trials of vaccination that were halted due to brain inflammation The recombinant sub-unit vaccine was domain without the immunodominant SAPA protective in mice

Demonstration of synthesis of (sEDIII-2) 
Epstein-Barr virus

EBNA1, the viral protein expressed in all EBV-associated malignancies; truncated EBNA1 (E1 $\triangle G A$, codons 390-641) was expressed as a secretory protein with an $\mathrm{N}$ terminal polyhistidine tag

Hand, foot and mouth disease

VP1, one of the major immunogenic capsid proteins of human enterovirus 71

(human enterovirus 71)

Helicobacter pylori infection

Hepatitis B virus

Hepatitis C virus

Human hookworm

(Necator

americanus)

Human

immunodeficiency

virus type 1

Human

papillomavirus

Human

schistosomiasis

(Schistosoma

Alkyl hydroperoxide reductase (AhpC)

Hepatitis B surface antigen (HBsAg)

E1E2 protein, which consists of E1 residues 187-346 and E2 residues 381-699

$N$. americanus glutathione S-transferase (Na-GST-1)

Gag protein

Major capsid protein, L1, for human papillomavirus type 16 the extracellular domain of a unique $S$. mansoni tetraspanin
Recombinant $\mathrm{E} 1 \Delta \mathrm{GA}$ was demonstrated

to be immunogenic in mice

$9 \mathrm{kDa}$ recombinant protein corresponding to
Recombinant VP1 protein was immunogenic in mice

Protection against infection was demonstrated in mice

Production and purification of VLPs that have potential as a superior vaccine to

${\text { Engerix- }{ }^{\circledR}}^{\circledR}$

E1E2 protein was immunogenic in rabbits

Scale-up of production was demonstrated for initial phase 1 clinical testing

Development of 20L scale production was demonstrated 
mansoni)

Influenza virus A (avian origin)

Influenza virus A (pandemic swine origin)

Japanese encephalitis virus

Leptospirosis

(Leptospira spp)

Malaria

(Plasmodium

berghei)

Malaria

(Plasmodium

falciparum)

Malaria

(Plasmodium vivax)
Recombinant neuraminidase (rNA) antigen

H1N1 hemagglutinin (HA) protein

Viral envelope protein (E)

Leptospiral immunoglobulin-like (Lig) protein LigANI and the immunodominant lipoprotein LipL32

Circumsporozoite protein (CS) multimerized by fusion to the measles virus nucleoprotein (N) known to auto-assemble in yeast in large-size ribonucleoprotein rods (RNPs)

Merozoite surface protein 1 (MSP-1), comprising $43 \mathrm{~N}$-terminal MSP-1 residues

(the 19 residue MSP-1 signal sequence, which is removed by processing in

baculovirus, plus 24 residues from $\mathrm{N}$ terminal block 1) and the adjacent 16 amino acid residues, and other variants

Apical membrane antigen-1 AMA-1
The recombinant antigen induced an

immunoprotective response in mice

Recombinant production of endotoxin-free H1N1 HA was demonstrated

Immunogenicity and protective efficacy were demonstrated in mice.

Recombinant proteins produced in E. coli have demonstrated variable results.

LigANI and LipL32 from P. pastoris retained the antigenic characteristics of the native proteins

Subcutaneous immunization of mice with heat-inactivated whole

$P$. pastoris expressing N-CS RNPs provided significant reduction of parasitemia after intradermal challenge with a high dose of parasites

Immunogenicity was demonstrated in rabbits

Secreted recombinant forms of AMA-1 were demonstrated to be immunogenic in 
Norovirus

Capsid protein (strain VA387, genogroup II.4)

Toxoplasmosis

(Toxoplasma

gondii)
Oral administration of yeast extracts

without an adjuvant stimulated an

appropriate immune response in mice

\section{Chimeric surface antigen 1 and 2 (SAG1/2)}

Vaccinated mice were significantly protected against lethal challenge with live $T$. gondii
(107) 